\title{
DO SMOKERS RESPOND TO HEALTH SHOCKS?
}

\author{
V. Kerry Smith, Donald H. Taylor, Jr., Frank A. Sloan, F. Reed Johnson, and William H. Desvousges*
}

Abstract-This paper reports the first effort to use data to evaluate how new information, acquired through exogenous health shocks, affects people's longevity expectations. We find that smokers react differently to health shocks than do those who quit smoking or never smoked. These differences, together with insights from qualitative research conducted along with the statistical analysis, suggest specific changes in the health warnings used to reduce smoking. Our specific focus is on how current smokers responded to health information in comparison to former smokers and nonsmokers. The three groups use significantly different updating rules to revise their assessments about longevity. The most significant finding of our study documents that smokers differ from persons who do not smoke in how information influences their personal longevity expectations. When smokers experience smoking-related health shocks, they interpret this information as reducing their chances of living to age 75 or more. Our estimated models imply smokers update their longevity expectations more dramatically than either former smokers or those who never smoked. Smokers are thus assigning a larger risk equivalent to these shocks. They do not react comparably to general health shocks, implying that specific information about smoking-related health events is most likely to cause them to update beliefs. It remains to be evaluated whether messages can be designed that focus on the link between smoking and health outcomes in ways that will have comparable effects on smokers' risk perceptions.

\section{Introduction}

$\mathrm{P}$ UBLIC policy toward cigarettes is about consumer sovereignty. Can people be trusted to interpret health warnings designed to reduce tobacco use, both what is on product labels and presented in public advertisements, as intended and to make rational smoking decisions? Evaluating smokers' reactions to health warnings requires an understanding of how people form their beliefs about the risks from smoking and update them when they encounter new information. This paper reports the first effort to use data to evaluate how new information, acquired through exogenous health shocks, affects people's longevity expectations. We find that smokers react differently to health shocks than do those who quit smoking or never smoked. These differences, together with insights from qualitative research conducted along with the statistical analysis, suggest specific changes in the health warnings used to reduce smoking.

Two areas of past research are relevant to our analysis. Hamermesh (1985) provided the first study about whether people's longevity expectations conform to life tables. ${ }^{1} \mathrm{He}$

Received for publication February 22, 1999. Revision accepted for publication November 7, 2000.

* North Carolina State Unviersity and Resources for the Future, Duke University, Duke University, Research Triangle Institute, and Triangle Economic Research, respectively.

Thanks are due to participants in NCSU Resource Economics, the NBER Health, and the MIT Public Finance workshops, Franklin Fisher, Jeff Harris, Glenn Harrison, Jim Poterba, and two anonymous referees for helpful comments on earlier drafts of this paper, as well as to Peter Rankin for research assistance, and to Alice Bowser, Jack Crawley, Kelly DeMarchis, Elizabeth Powell, Julia Smith, and Katherine Taylor for preparing drafts of this paper. Partial support for this research was provided by grant 034900 from the Robert Wood Johnson Foundation in support of the Substance Abuse Policy Research Program.

${ }^{1}$ The objective of his research was to consider the subjective time horizon that people use in making their decisions. As Hamermesh notes reported strong evidence that people act as if they extrapolated from changing life tables when they form subjective time horizons and seem to be aware of improvements in life expectancy. Nonetheless, subjective longevity perceptions do not accurately correspond to actuarial counterparts. In his surveys, respondents tend to base their beliefs disproportionately on their relatives' longevity. ${ }^{2}$

The second area concerns people's subjective beliefs about other sources of risk. In these cases, there is considerable evidence that people distinguish between what they believe is the average or population risk of an adverse event and their personal likelihood of experiencing the same outcome (Fischhoff, Bostrom, \& Quadrel, 1993). There is disagreement, however, about whether these distinctions between personal and population risks are warranted. In the smoking context, Viscusi $(1990,1991,1992)$ has argued that smokers overestimate the risk of getting lung cancer from smoking. Others have suggested this conclusion is not warranted. ${ }^{3}$ However, none of these efforts have been able to observe how smokers and nonsmokers change their beliefs about their own risks after obtaining new information. Thus, this study is the first evaluation of how perceived smoking risk changes in response to personal risk information.

To explore this issue, we analyze panel data from the Health and Retirement Study (HRS) and evaluate how the survey participants changed their longevity expectations in response to health shocks. The HRS sample ranges in age from 51 to 61 , which is much older than the groups studied in most of the research on cigarette smoking. The literature's focus on younger consumers is, to some degree, logical because the habit generally begins before adulthood. However, it overlooks an important additional feature of

"Central to the theory of the utility-maximizing consumer is the role of the horizon. Yet there has been no comparable examination [to studies of price expectations] of how individuals form expectations about the horizons over which they maximize" (p. 389).

${ }^{2}$ In focus groups conducted with current smokers and former smokers, we found that many current smokers had formed an unintended conclusion from the public information programs. Some of the public service programs they encountered had emphasized how the lungs and heart recover in a few years after an individual stops smoking. These participants argued that because they were well within the ages realized by a grandparent, there was "plenty of time to quit and still realize the benefits" of cessation decisions. The messages implied for them that the health consequences could be avoided at any time they stopped smoking.

${ }^{3}$ Given the high fatality rate from lung cancer, Viscusi's question has been interpreted as implying death from lung cancer due to smoking. A number of analysts have questioned the Viscusi analysis. Hanson and Logue (1998) summarize the potential limitations from a legal perspective. One especially relevant to our work is their criticism of Viscusi's risk-perception question which suffers from a "third-person effect" by asking about the probability that 100 smokers will get lung cancer because of smoking rather than a personal risk. A second example can be found in Schoenbaum (1997) who argues, based on analyzing questions in wave 1 of the Health and Retirement Study that both men and women who were heavy smokers overestimate their probability of survival to 75 . 
smoking. The adverse health effects of smoking generally occur after fifty. Effective risk messages that encourage cessation decisions could help delay these health impacts. Our analysis is based on the 1992 and 1994 HRS data, including serious health events reported between the two surveys. These serious health conditions were classified into smoking-related cardiovascular, cerebrovascular, chronic lung conditions, and cancers as well as other significant health conditions not related to smoking (including some types of cancer (U.S. Department of Health and Human Services, 1989)). Our analysis also accounted for changes in preexisting conditions and in activity patterns during this time interval that could influence respondents' beliefs about their overall physical condition.

The findings are striking. Measuring perceived risk as the likelihood of living to age 75 or older, current smokers are more pessimistic than nonsmokers. Smokers also differed from nonsmokers in using new information to update their longevity expectations. Smokers were particularly sensitive to their own smoking-related illnesses and to increasing limitations in their ability to undertake physical activities. Former smokers and those who never smoked reacted to a much wider range of health-related signals. Thus, our findings help reconcile conflicts in the literature and suggest a redirection in information policy. More specifically, smokers do, as Viscusi's results would imply initially, state lower subjective probabilities of living to 75 . However, when these respondents are grouped by amount smoked, the longevity expectations of heavy smokers do not reflect the adjustments downward in these assessments for this behavior that would be required for them to be consistent with what actually happens to heavy smokers. These findings confirm Schoenbaum's (1997) conclusion. In addition, our analysis adds to this earlier work a clear indication that smokers responded to personal experiences with diseases that are linked to smoking behavior. We also find in related research that smokers react more to information that smoking affects their ability to undertake common physical activities (such as walking a block, climbing stairs, or lifting ten pounds) later in their lives than to information about the effects of continued cigarette smoking on the risk of premature death. As a result, generalized messages about the hazards of smoking may be less effective than information about smoking-induced activity restrictions.

Section II discusses the past evidence on how risk perceptions respond to information. The third section describes the samples and the variables used in our analysis. It also presents results for cross-tabulations to test our basic hypothesis, and then outlines the risk-updating model. Section IV reports updating model estimates with two samples: respondents who answered the longevity question in both waves, and a subsample of respondents with a living spouse in wave 2 who answered the longevity question in both waves. This second group allows consideration of how family members' health shocks affected a respondent's sub- jective beliefs. The last section concludes with a discussion of how our findings relate to economic models of smoking behavior as well as to efforts to promote cessation.

\section{Modeling Subjective Risk Perceptions}

Viscusi (1985) first proposed using a Bayesian updating framework for subjective risk perceptions. Since then, it has been used in a number of applications in which stated beliefs, safety decisions, or both (Viscusi \& Evans, 1998; Evans \& Viscusi, 1991; Smith et al., 1990; Viscusi \& O'Connor, 1984) involved a risk assessment process. Our analyses of subjective smoking risks as measured by perceived longevity will be undertaken in two ways. The first involves simple $c h i$-square tests of two primary hypotheses and the second includes several different estimates of the risk updating model. The first hypothesis we test maintains that smokers, former smokers, and those who never smoked have different longevity perceptions. The second hypothesis stems from observations of smokers' and former smokers' attitudes expressed in focus groups. The hypothesis based on these attitudes suggests that smokers and former smokers react differently to unanticipated, exogenous health shocks related to smoking in comparison to those health shocks that were not smoking related. Before turning to the specific details of our tests of these hypotheses, it is important to place the advantages offered by the HRS panel structure in context with what has been possible in past research.

Three types of applications have used some variant of the updating model for explaining subjective risks. In the first, respondents appraise the likelihood of different types of events using a comparable scale. Often these are "thirdperson" questions asking subjects about an activity (or a process) for the "typical" participant (or under normal conditions). This distinction in framing may partially explain Viscusi's conclusions about smokers' risk perceptions in comparison to other analysts' findings. ${ }^{4}$ Viscusi's analysis was based on asking "Among 100 cigarette smokers, how many do you think will get lung cancer because they smoke?" This is a variant of a third-person question.

People's judgments about the lethality of various potential causes of death depend on how the questions are asked. (See Fischhoff \& MacGregor (1983) for an early example of

\footnotetext{
${ }^{4}$ Schoenbaum (1997) reported estimates of the perceived probability of survival to age 75 of $0.501(0.281)$ in comparison to life table estimates of 0.263 for men and perceived longevity of $0.601(0.268)$ compared to the life table estimates of 0.308 for women. These differences are large. (Standard errors are in parentheses.) However, it appears that his tests treat the subjective survival probability as a random variable and the values from the life table as fixed. Actually, both measures should be considered random variables. Thus, his conclusions about statistical significance appear to be conditional to this maintained assumption. Equally important, one of his conclusions does not match the numerical estimates for other groups. The subjective survival probabilities for light smokers (both men and women) were less than the survival probabilities from life tables. The differences are small: 0.579 versus 0.594 for men and 0.625 versus 0.747 for women. Nonetheless, this record appears to be at odds with his conclusion that "in contrast to Viscusi's findings, no smoking group appeared to overestimate the likely mortality effect of smoking" (p. 758).
} 
these format effects.) Although this line of research primarily considers third-person judgments, an early study suggests that providing information in a personal format is necessary. Smith et al. (1987) compare a sample of respondents receiving information about their own exposures to radon and find that their answers to questions about the "general" seriousness of the health risks from radon exposure are quite different from a "personalized" risk question. In that application, the risk perceptions assessed via general questions do not change in response to new risk information whereas the personalized questions do.

The second class of applications is in the context of contingent valuation surveys. Respondents are asked about risk perceptions for a specified activity, and the interview then presents information relevant to that activity. Often the framing and content of the information presented varies across respondents. Perceptions are then elicited at the end of the interview. As a rule, the studies ask about one or more precautionary actions that are described as being available at varying costs. ${ }^{5}$ These responses, together with the revised assessments, are then used to develop estimates of the participants' marginal willingness to pay to reduce the risks involved. ${ }^{6}$ The third set of applications uses a panel structure together with different information treatments concerning the actual risks that face respondents. These studies evaluate the influence of information on participants' risk perceptions and behavior. Although the individuals may well recognize that the materials are part of a research study, both the information and the sources of risk are real and relevant to their activities. In an application for the indoor air pollutant, radon, mitigation decisions were influenced by risk perceptions (Smith, Desouvsges, \& Payne, 1995). Nonetheless, these three classes of studies are not able to consider how "personalized" risk signals affect perceived risk. The conventional wisdom of risk communication (Fischhoff, 1989, Slovic et al. 1985) holds that indirect experience from public information programs or news media causes people to believe the events at risk can happen, but the net effects on behavior are smaller than what might be expected. One explanation is that people believe their personal experience would be better than the "average" conditions reported in these programs.

\footnotetext{
${ }^{5}$ Examples include Sloan et al. (1998), Viscusi, Magat, and Huber (1987), Krupnick and Cropper (1992), Poe and Bishop (1992) and a number of other contingent valuation studies involving risk.

${ }^{6}$ Another category of study that has not been used as much in evaluating risk perceptions involves experimental methods. In these cases, a monetary incentive is given to promote accurate assessments. To do this, a scoring rule computes a reward (or score) based on the respondent's stated probability and on the event that actually occurs. Veloso (1998) used these techniques, along with Viscusi's risk-perception question, to evaluate the effects of two kinds of information. The first involved information about alleged actions of cigarette companies from the 1930s through the 1950s collected from litigation and the second about cigarette smoke and health consequences of smoking from public health reports. A small pilot study confirmed that information affected risk perception elicited with these scoring incentives (Veloso, 1998).
}

As described in the next section, the Health and Retirement Study includes information on longevity expectations (which we treat as risk perceptions), health history, smoking behavior, and other personal characteristics from a large panel of older Americans. Unlike previous studies, we can observe changes in risk perceptions following an actual health shock. These data enable us to test whether smokers adjust subjective risks differently from nonsmokers.

\section{Data}

Two waves of the Health and Retirement Study (HRS, waves 1 and 2) provide the basis for our analysis (Juster \& Suzman, 1995). The HRS is a national panel study of birth cohorts 1931-1941 and their spouses, if married. Respondents to wave 1 HRS, conducted in 1992, ranged from 51 to 61 years of age (with some spouses being younger or older than this). The baseline included 12,652 persons $(7,600$ households), with oversamples for Mexican-Americans, blacks, and residents of Florida (Juster \& Suzman, 1995). The objectives underlying the development of the panel were: (a) to explain antecedents and consequences of retirement; (b) to examine the relationship between health, income, and wealth over time, as well as life cycle patterns of wealth accumulation and consumption; (c) to monitor work and disability interactions; and (d) to provide the baseline for a long-term epidemiological study on aging (Juster \& Suzman, 1995). Baseline interviews were conducted in respondents' homes, with telephone follow-ups scheduled every two years for twelve years. HRS contains extensive information on health behaviors, health and functional status, and individual's subjective perception of longevity. We analyzed two samples from the survey. The first consists of all persons responding to wave $2 \mathrm{HRS}$ who also responded to wave $1(N=11,492)$. The second sample consists of the individuals that could be identified as couples in wave 2 (paired sample). Both members of the couple are included in this sample $(N=8,952)$.

\section{A. Variables Used in the Analysis}

The dependent variables are each respondent's self-reported subjective probabilities of living to 75 or more years of age. ${ }^{7}$ Each respondent in a household was asked this

\footnotetext{
${ }^{7}$ In wave 2 , the wording asking about longevity was comparable to wave 1 . The primary difference arose because respondents were asked to use a different scale for their answers. For both waves, we have converted the dependent variables to a $0-1.0$ scale. The specific texts for the two questions are given as follows, only the initial explanation changed and scale changed. Wave 1 (longevity question): "Next I would like to ask you about the chances that various events will happen in the future. Using any number from zero to ten where 0 equals absolutely no change and 10 equals absolutely certain ... What do you think are the chances that you will live to be 75 or more?" Wave 2 (longevity question): "Now I am going to ask about the chances of various events happening to you. Please answer the questions in terms of percent chance. Percent chance must be a number from 0 to 100 , where " 0 " means there is absolutely no chance, and " 100 " means that it is absolutely certain... What is the percent chance you will live to be 75 or more?"
} 
question in each wave. Responses are rescaled to the zeroto-one interval. The explanatory variables are demographic variables (describing age, education, gender, race, marital status, whether parents were alive), current (as of the time of interview) smoking status, indicators of cognitive abilities, and the three health measures discussed earlier. These are the health-shock variables, variables defined to identify situations with no change in serious preexisting health conditions related to smoking, and deteriorations between the two waves in upper-body and lower-body activity limitations. Summary statistics and the specific definitions are given in table 1. For the paired subsample, we also include variables for the spouse's health shocks and smoking status.

All health shocks are events that occurred between the waves and represent the onset of new, serious health conditions. For example, if a respondent reported at wave 2 a heart attack that occurred since wave 1 , and reported no history of heart attack, this is recorded as a health shock. We classify health shocks as smoking related and general. Smoking-related health shocks are those health events found to have an elevated relative risk for death among smokers by the Surgeon General (U.S. Department of Health and Human Services, 1989). These are cardiovascular and cerebrovascular diseases, cancers that are related to smoking, and severe chronic lung disease such as emphysema, which are reported in the HRS records. These conditions are major sources of morbidity and mortality among this age group and for older persons. ${ }^{8}$

To ensure that health shocks are serious health events and hence powerful "shocks," we include only reports of heart attack, congestive heart failure, and stroke requiring that the person report at least three days in the hospital between waves 1 and 2 (although the data did not indicate that the reported shock was responsible for a particular hospital stay). ${ }^{9}$ For newly occurring cases of severe chronic lung disease (such as, bronchitis and emphysema), the respondent had to state that this illness limited his or her ability to work or do household chores. For cancers that are smoking related, no hospital stay was required because diagnosis is more clear-cut, and the treatment for some types of cancer has been shifted to outpatient facilities. As a result, it is

\footnotetext{
Analysis of these types of differences in risk questions using different scales as well as modest changes in the wording or interview formats (such as mail versus telephone) from the radon studies discussed earlier did not affect the empirical estimates of updating models (Smith, Desvousges, Fisher, \& Johnson, 1987).

${ }^{8}$ The leading causes of death for persons aged 45-64 in 1995 (with deaths per 100,000 in parentheses) for males were: (1) heart disease (308.2); (2) cancer (298.7); (3) accidents (42.9); (4) stroke (33.3); and (5) HIV/AIDS (31.2). For females: (1) cancer (240.1); (2) heart disease (120.7); (3) stroke (26.2); (4) chronic obstructive pulmonary disease (23.6); and (5) diabetes (20.4) [U.S. Bureau of the Census, 1998].

${ }^{9}$ This screen was imposed because preliminary analyses showed some implausible reports of health shocks with no corresponding hospital stay. The primary goal of all screens used was to verify that the newly reported condition, whether smoking-related or not, was serious.
}

plausible that a person could develop cancer but not spend three days in a hospital between waves 1 and 2 .

For general health shocks, we use the onset of serious medical conditions that are specifically collected by HRS and that are not linked conclusively to smoking. General medical shocks include the onset of diabetes that resulted in a hospitalization (suggesting newly diagnosed, uncontrolled, or severe diabetes), an accident in which a person was knocked unconscious and spent at least three days in a hospital between waves 1 and 2, surgery to replace a joint after a fracture, and the report of any other serious medical condition with a three-day hospital stay. Finally, the new occurrence of a cancer in an organ not identified as smoking related (such as prostate cancer) also is considered a general medical shock.

The preexisting health states include two measures of heart disease: one for smoking related cancers, and one for other cancers. Heart conditions are treated as qualitative variables $(0,1)$ identifying cases in which a condition existed but did not get worse. They are separated into: (a) cases with preexisting high blood pressure in wave 1 (but no history of heart attacks, strokes, or congestive heart failure) who did not experience a heart attack, congestive heart failure, or stroke between waves 1 and 2; and (b) cases in which the respondent reported having a history of heart disease in wave 1 but did not have a new occurrence or report worsening of heart disease. Cancer measures are also 0,1 variables for which respondents reported a smokingrelated cancer at wave 1 , but did not have it spread to another organ between wave 1 and 2 . Only cancers reported as occurring in 1982 or later are included. The coding for these variables highlights nonoccurrence of further problems. ${ }^{10}$

The last set of health indicators used the two waves to identify changes in reported lower-body and upper-body limitations. These measures are based on reports of specific activity limitations. ${ }^{11}$ We use the count of reported limitations to evaluate whether the limitations increased, stayed the same, or improved between the two waves. The defini-

\footnotetext{
${ }^{10}$ We investigated the same $(0,1)$ coding using situations with preexisting cancers that were not smoking related and did not spread but found they were insignificant in risk updating. As a result, they are not discussed further.

${ }^{11}$ The change in activities variables were defined for upper-body, lowerbody, and fine motor activities. Upper-body was associated with a respondent reporting an increase in limitations of upper-body activities between wave 1 and 2 . Lower-body was associated with a respondent reporting an increase in limitations of lower-body activities between wave 1 and 2 . Fine motor followed this format if the respondent experienced an increase in limitations of fine motor skills between wave 1 and 2 . The positive health information variables were defined based on preexisting conditions of high blood pressure, heart disease, and cancer: the first of these if a respondent had high blood pressure, no history of heart disease, and no heart-related health shock between wave 1 and wave 2; the second if a respondent had history of heart disease at wave 1 but no worsening by wave 2; and the last if a respondent had smoking-related cancer in wave 1 but no spreading to a new organ by wave 2 .
} 
Table 1.-Health Information Variables Based on Changes Between Waves 1 and 2

\begin{tabular}{|c|c|c|}
\hline Condition & $\begin{array}{l}\text { Hospital Stay Between } \\
\text { Wave } 1 \text { and } 2 \text { Required }\end{array}$ & $\begin{array}{l}\text { Proportion of Sample } \\
\text { Experiencing Health Conditions }^{\mathrm{a}}\end{array}$ \\
\hline Smoking Related Health Shocks ${ }^{\mathrm{b}}$ & & $\begin{array}{c}0.038 \\
(0.19)\end{array}$ \\
\hline Myocardial infarction & Yes, 3-day & $\begin{array}{c}0.014 \\
(0.12)\end{array}$ \\
\hline Congestive heart failure & Yes, 3-day & $\begin{array}{c}0.009 \\
(0.09)\end{array}$ \\
\hline Stroke & Yes, 3-day & $\begin{array}{c}0.006 \\
(0.07)\end{array}$ \\
\hline Chronic lung conditions (bronchitis/emphysema) & $\begin{array}{l}\text { No (condition had to limit ability to } \\
\text { work or do household chores) }\end{array}$ & $\begin{array}{c}0.024 \\
(0.15)\end{array}$ \\
\hline $\begin{array}{l}\text { Smoking-related cancers (sites reported: bladder, cervix, esophagus, } \\
\text { kidney, larynx, lip, lung, mouth/oral, pancreas, throat) }\end{array}$ & No & $\begin{array}{l}0.006 \\
(0.08)\end{array}$ \\
\hline General Health Shocks & & $\begin{array}{l}0.056 \\
(0.23)\end{array}$ \\
\hline $\begin{array}{l}\text { Nonsmoking-related cancer (sites reported: abdomen, arm, } \\
\text { back, blood, bone/bone marrow, brain, breast, colon, ear, } \\
\text { endometrium, eye, face, female organs, gastrointestinal, } \\
\text { head, jaw, leg, liver, lymph nodes, neck, ovary, pelvis, } \\
\text { prostate, spine, stomach, thyroid) }\end{array}$ & No & $\begin{array}{c}0.01 \\
(0.11)\end{array}$ \\
\hline Diabetes & $\begin{array}{l}\text { Yes, that resulted in a hospitalization } \\
\text { specifically for diabetes }\end{array}$ & $\begin{array}{l}0.004 \\
(0.06)\end{array}$ \\
\hline Broken bone and joint replacement/repair surgery & No & $\begin{array}{l}0.00062 \\
(0.25)\end{array}$ \\
\hline Knocked unconscious due to a head injury & Yes, 3 days & $\begin{array}{l}0.002 \\
(0.04)\end{array}$ \\
\hline Other serious health conditions ${ }^{c}$ & Yes, 3 days & $\begin{array}{r}0.039 \\
(0.19)\end{array}$ \\
\hline History of Disease Without Worsening (Positive Health Message) & & $\begin{array}{c}0.11 \\
(0.31)\end{array}$ \\
\hline $\begin{array}{l}\text { High blood pressure (wave 1) without history of heart attack, } \\
\text { heart failure or stroke and none of these by wave } 2\end{array}$ & No & $\begin{array}{c}0.004 \\
(0.062)\end{array}$ \\
\hline $\begin{array}{l}\text { Smoking-related cancer reported in wave } 1 \text { (1982 or later) } \\
\text { that did not spread to a new site by wave } 2\end{array}$ & No & $\begin{array}{c}0.007 \\
(0.086)\end{array}$ \\
\hline History of coronary heart disease in wave 1 & No & $\begin{array}{r}0.097 \\
(0.30)\end{array}$ \\
\hline Worsening of Activity Limitations & & $\begin{array}{c}0.513 \\
(0.500)\end{array}$ \\
\hline Increase in lower-body limitations (e.g. walking, climbing stairs) & No & $\begin{array}{c}0.227 \\
(0.419)\end{array}$ \\
\hline $\begin{array}{l}\text { Increase in upper-body limitations (e.g. lifting } 10 \mathrm{lb} \text {. objects, } \\
\text { pushing large items such as chairs across the floor) }\end{array}$ & No & $\begin{array}{c}0.335 \\
(0.472)\end{array}$ \\
\hline
\end{tabular}

tion for smoking status is based on their reported status in wave $2 .{ }^{12}$

\section{Results}

The simplest hypothesis tests compare the longevity expectations for HRS respondents in wave 1 and wave 2 using two classification schemes. The first classification compares the longevity perceptions across those groups classified by the smoking status of each respondent, as reported in wave 2. A chi-square test of whether the distribution of responses to the HRS perceived-longevity question (live to 75 or more) are comparable rejects this null hypothesis for current

\footnotetext{
${ }^{12}$ For individuals, smoking status refers to the individual; for couples, the samples are defined according to the smoking status of the primary respondent to the HRS.
}

smokers, former smokers, and those who never smoked. This is true for both waves. (That is, in wave 1 , the test statistic is $\chi^{2}(20)=155.84$; in wave 2 , it is $\left.\chi^{2}(20)=164.07\right) .{ }^{13}$

The second hypothesis maintains that current smokers, former smokers, and those who never smoked react differently to health shocks. Moreover, we expect that current smokers would be responsive to only smoking-related health shocks. This hypothesis is tested using chi-square analysis tests for cross-tabulations for each group. This approach imposes fewer maintained assumptions than a formal updating model. The top half of table 2 summarizes these $c h i$-square statistics with the $p$-value for rejection of the null hypothesis of comparable distributions between

\footnotetext{
13 These tests did not use the sampling weights for the HRS survey.
} 
Table 2.-ChI-Square Test of Subsamples and Health Shocks

\begin{tabular}{lccccc}
\hline \hline & \multicolumn{3}{c}{ Health Shocks } \\
\cline { 2 - 3 } Longevity Perception & Smoking & & General \\
\cline { 2 - 3 } \cline { 5 - 6 } Measure/Smoking Behavior & With & Delete & & With & Delete \\
& focal & focal & & focal & focal \\
\hline Level of Longevity Perceptions & & & & \\
in Wave 2 & & & & \\
Smoker & 66.09 & 62.27 & 27.08 & 26.74 \\
& $(0.00)$ & $(0.00)$ & $(0.46)$ & $(0.48)$ \\
Former & 154.83 & 149.70 & 156.92 & 155.42 \\
& $(0.00)$ & $(0.00)$ & $(0.00)$ & $(0.00)$ \\
Never & 94.96 & 95.68 & 63.95 & 60.21 \\
& $(0.00)$ & $(0.00)$ & $(0.00)$ & $(0.00)$ \\
Difference in Longevity Perceptions & & & & \\
(Wave 2-Wave 1) & & & & \\
Smoker & 175.38 & 172.19 & 69.43 & 67.39 \\
& $(0.00)$ & $(0.00)$ & $(0.95)$ & $(0.97)$ \\
Former & 197.79 & 194.94 & 229.81 & 223.71 \\
& $(0.00)$ & $(0.00)$ & $(0.00)$ & $(0.00)$ \\
Never & 177.56 & 175.14 & 138.32 & 131.37 \\
& $(0.00)$ & $(0.00)$ & $(0.01)$ & $(0.02)$ \\
\hline The numbers are $\chi^{2}$ statistics. ( $p$-values in parentheses.) & & & &
\end{tabular}

those experiencing and those not experiencing each of the two types of health shocks. The first and the third columns in the top panel of the table summarize our findings. Current smokers react to only smoking-related shocks, and the other groups modify their longevity expectations in response to both types of health shocks.

To evaluate the plausibility of the HRS's subjective longevity question, we consider whether respondents who died between waves 1 and 2 and between waves 2 and 3 were "rational" in anticipating death. We consider whether respondents' subjective beliefs about personal longevity in wave 1 predicted death between waves 1 and 2 , and whether the wave 2 longevity perception predicted death between waves 2 and 3. This evaluation assumes that a high subjective appraisal of living to 75 or more is inconsistent with death between the waves (that is, an "irrational" expectation). Analyses of both subsamples confirm deaths between waves 1 and 2 and between 2 and 3 support this hypothesis; higher expectations of living to 75 or more are associated with a reduced likelihood of death, after controlling for demographic variables that would be likely to influence death. ${ }^{14}$ This finding indicates that the subjective longevity measures in HRS seem to behave consistently with an individual's unobserved health status and associated life expectancy.

The HRS longevity perception question avoids providing information that could be used as an anchor. Nonetheless, other analysts have found that some respondents give implausible answers that could indicate they either did not understand or did not devote effort to answering the ques-

\footnotetext{
${ }^{14}$ The HRS confirms all deaths but does not report the cause of death, so we could not distinguish accidents from deaths due to chronic conditions. However, this limitation makes our test a conservative gauge of the plausibility of the longevity perceptions. See Taylor, Smith, and Sloan (1999).
}

tions involved. For example, Hurd, McFadden, and Gan (1998) found (based on analysis of wave 1 of the HRS) that some respondents reported $0.0,0.5$, or 1.0 (after normalizing the 0 -to-10 responses by 10) on several of the eight subjective likelihood questions. These types of responses would be unlikely. Consequently, Hurd et al. labeled them "focal responses." Unfortunately, using this definition, it is difficult to distinguish implausible responses that would be judged as "focal" from plausible subjective beliefs. Simple comparisons across different sources of risk do not seem to provide an objective basis to distinguish consistent from inconsistent responses.

To evaluate the potential for focal responses, we extend the Hurd et al. definition for focal responses using the HRS questions about living to 75 or more and about living to 85 or more. Our definition relies on reasonable consistency between the two answers. That is, for the second response to be consistent, it must be based on the premise that respondents assume that they will live to 75 . Thus, we should not observe responses to both questions that were equal and corresponded to the focal values of $0.0,0.5$, and 1.0. Based on this reasoning, focal responses are defined for our analyses as cases in which an individual answers the same focal (that is, $0.0,0.5$, or 1.0 ) value to both the "live to 75 or older" and "live to 85 or older" questions in wave 2 . We hypothesize that people who understand the longevity question would distinguish these cases. In the absence of some misunderstanding of these questions, the likelihood that the two responses would be constant and equal to these simple anchors would seem to be negligible. ${ }^{15}$ Columns 2 and 4 in the upper panel of table 3 delete focal observations and recompute the tests for the effects of health shocks. ${ }^{16}$ None of our conclusions would change by restricting the sample to this subset.

A difficulty with these unstructured tests is that they do not control for other differences across the groups that could be generating these results. Moreover, in the case of the health shocks, they do not imply that the shocks themselves lead to revisions in the longevity perceptions. To address this question, we compare differences between wave 2 and wave 1 longevity perceptions.

These tests are given in the lower panel of table 2. We compare those experiencing each type of health shock with those who did not test whether they have different distributions for the differences between wave 2 and wave 1 longevity expectations. These tests are repeated by type of respondent, type of health shock, and for samples with and without focal responses. They confirm all our results using

\footnotetext{
${ }^{15}$ Indeed, Hurd and McGarry (1995) also note that there was broad consistency in the relationships between live-to-75 and live-to- 85 responses based on their review of the wave 1 responses.

${ }_{16}$ Our conclusions from tests for differences in longevity perceptions between the three groups of respondents were not affected by deleting focal responses: for wave $1 \chi^{2}=106.45$; wave $2 \chi^{2}=166.69$. Both imply clear rejection of equal distributions of longevity perceptions across the three groups.
} 
Table 3.-Risk-Updating Model for Live-to-75 in Wave 2 (Live 75W2) for Full and Paired Sample

\begin{tabular}{|c|c|c|c|c|c|c|}
\hline \multirow[b]{2}{*}{ Model \# obs: } & \multicolumn{3}{|c|}{ Full Sample } & \multicolumn{3}{|c|}{ Paired Sample } \\
\hline & $\begin{array}{c}\text { Current* } \\
2,381\end{array}$ & $\begin{array}{c}\text { Former } \\
3,931\end{array}$ & $\begin{array}{c}\text { Never } \\
3,672\end{array}$ & $\begin{array}{c}\text { Current } \\
1,712\end{array}$ & $\begin{array}{c}\text { Former } \\
3,158\end{array}$ & $\begin{array}{l}\text { Never } \\
2,914\end{array}$ \\
\hline Intercept & $\begin{array}{l}0.2169 \\
(3.19)\end{array}$ & $\begin{array}{l}0.3214 \\
(5.91)\end{array}$ & $\begin{array}{l}0.1516 \\
(3.15)\end{array}$ & $\begin{array}{l}0.2443 \\
(3.28)\end{array}$ & $\begin{array}{l}0.3187 \\
(5.46)\end{array}$ & $\begin{array}{l}0.1215 \\
(2.38)\end{array}$ \\
\hline Longevity expectation wave 1 & $\begin{array}{c}0.4885 \\
(24.57)\end{array}$ & $\begin{array}{c}0.4734 \\
(32.39)\end{array}$ & $\begin{array}{c}0.4963 \\
(30.77)\end{array}$ & $\begin{array}{c}0.4787 \\
(20.26)\end{array}$ & $\begin{array}{c}0.4749 \\
(28.89)\end{array}$ & $\begin{array}{c}0.5097 \\
(28.24)\end{array}$ \\
\hline Smoking-related health shocks & $\begin{array}{l}-0.1237 \\
(-3.84)\end{array}$ & $\begin{array}{l}-0.0692 \\
(-3.18)\end{array}$ & $\begin{array}{l}-0.1095 \\
(-3.31)\end{array}$ & $\begin{array}{l}-0.1526 \\
(-3.72)\end{array}$ & $\begin{array}{l}-0.0667 \\
(-2.62)\end{array}$ & $\begin{array}{l}-0.0972 \\
(-2.52)\end{array}$ \\
\hline General health shocks & $\begin{array}{l}0.0076 \\
(0.27)\end{array}$ & $\begin{array}{l}-0.0665 \\
(-3.69)\end{array}$ & $\begin{array}{l}-0.0551 \\
(-2.74)\end{array}$ & $\begin{array}{l}-0.0052 \\
(-0.15)\end{array}$ & $\begin{array}{l}-0.0590 \\
(-2.89)\end{array}$ & $\begin{array}{l}-0.0359 \\
(-1.53)\end{array}$ \\
\hline $\begin{array}{l}\text { High blood pressure, with no worsening } \\
\text { in condition }\end{array}$ & $\begin{array}{l}-0.1460 \\
(-1.38)\end{array}$ & $\begin{array}{l}-0.1685 \\
(-3.25)\end{array}$ & $\begin{array}{l}-0.1510 \\
(-1.93)\end{array}$ & $\begin{array}{l}-0.1378 \\
(-1.20)\end{array}$ & $\begin{array}{l}-0.1765 \\
(-3.04)\end{array}$ & $\begin{array}{l}-0.1608 \\
(-1.79)\end{array}$ \\
\hline Heart disease, with no worsening & $\begin{array}{l}-0.0441 \\
(-2.12)\end{array}$ & $\begin{array}{l}-0.0383 \\
(-2.95)\end{array}$ & $\begin{array}{l}-0.0347 \\
(-2.22)\end{array}$ & $\begin{array}{l}-0.0617 \\
(-2.52)\end{array}$ & $\begin{array}{l}-0.0460 \\
(-3.25)\end{array}$ & $\begin{array}{l}-0.0217 \\
(-1.24)\end{array}$ \\
\hline Smoking-related cancer, with no worsening & $\begin{array}{l}0.0590 \\
(1.05)\end{array}$ & $\begin{array}{l}0.0670 \\
(1.32)\end{array}$ & $\begin{array}{l}0.0041 \\
(0.07)\end{array}$ & $\begin{array}{l}0.0177 \\
(0.19)\end{array}$ & $\begin{array}{l}0.0727 \\
(1.29)\end{array}$ & $\begin{array}{l}0.0102 \\
(0.15)\end{array}$ \\
\hline Reports increase in upper-body limitations & $\begin{array}{l}-0.0565 \\
(-3.49)\end{array}$ & $\begin{array}{l}-0.0566 \\
(-4.64)\end{array}$ & $\begin{array}{l}-0.0398 \\
(-3.17)\end{array}$ & $\begin{array}{l}-0.0712 \\
(-3.69)\end{array}$ & $\begin{array}{l}-0.0504 \\
(-3.65)\end{array}$ & $\begin{array}{l}-0.0358 \\
(-2.56)\end{array}$ \\
\hline Reports increase in lower-body limitations & $\begin{array}{l}-0.0517 \\
(-3.37)\end{array}$ & $\begin{array}{l}-0.0210 \\
(-1.99)\end{array}$ & $\begin{array}{l}-0.0263 \\
(-2.44)\end{array}$ & $\begin{array}{l}-0.0398 \\
(-2.12)\end{array}$ & $\begin{array}{l}-0.0227 \\
(-1.94)\end{array}$ & $\begin{array}{l}-0.0159 \\
(-1.32)\end{array}$ \\
\hline Parent of same sex as respondent alive & $\begin{array}{l}0.0209 \\
(1.42)\end{array}$ & $\begin{array}{l}0.0309 \\
(2.78)\end{array}$ & $\begin{array}{l}0.0134 \\
(1.33)\end{array}$ & $\begin{array}{l}0.0166 \\
(0.92)\end{array}$ & $\begin{array}{l}0.0323 \\
(2.50)\end{array}$ & $\begin{array}{l}0.0151 \\
(1.31)\end{array}$ \\
\hline Age & $\begin{array}{l}0.0020 \\
(1.53)\end{array}$ & $\begin{array}{l}0.0011 \\
(1.08)\end{array}$ & $\begin{array}{l}0.0038 \\
(4.41)\end{array}$ & $\begin{array}{l}0.0015 \\
(1.07)\end{array}$ & $\begin{array}{l}0.0010 \\
(0.92)\end{array}$ & $\begin{array}{l}0.0041 \\
(4.41)\end{array}$ \\
\hline Spouse had smoking-related shock & & & & $\begin{array}{l}-0.0286 \\
(-0.84)\end{array}$ & $\begin{array}{l}-0.0275 \\
(-1.00)\end{array}$ & $\begin{array}{l}-0.050 \\
(-1.94)\end{array}$ \\
\hline Spouse had general health shock & & & & $\begin{array}{l}0.0084 \\
(0.27)\end{array}$ & $\begin{array}{l}-0.0269 \\
(-1.26)\end{array}$ & $\begin{array}{l}-0.0313 \\
(-1.41)\end{array}$ \\
\hline Spouse is a smoker & & & & $\begin{array}{l}-0.0080 \\
(-0.57)\end{array}$ & $\begin{array}{l}-0.0020 \\
(-0.17)\end{array}$ & $\begin{array}{l}-0.0325 \\
(-2.43)\end{array}$ \\
\hline $\log \mathrm{L}$ & -1306.9 & -1809.1 & -1662.5 & -894.5 & -1365.5 & -1218.7 \\
\hline Rho & $\begin{array}{l}-0.2361 \\
(-1.96)\end{array}$ & $\begin{array}{l}-0.3731 \\
(-3.67)\end{array}$ & $\begin{array}{l}-0.4819 \\
(-4.20)\end{array}$ & $\begin{array}{l}-0.0882 \\
(-0.56)\end{array}$ & $\begin{array}{l}-0.2749 \\
(-2.03)\end{array}$ & $\begin{array}{l}-0.3775 \\
(-2.74)\end{array}$ \\
\hline lambda & $\begin{array}{l}-0.6113 \\
(-1.98)\end{array}$ & $\begin{array}{l}-0.0864 \\
(-3.82)\end{array}$ & $\begin{array}{l}-0.1119 \\
(-4.57)\end{array}$ & $\begin{array}{l}-0.0225 \\
(-0.56)\end{array}$ & $\begin{array}{l}-0.0623 \\
(-2.07)\end{array}$ & $\begin{array}{l}-0.0854 \\
(-2.08)\end{array}$ \\
\hline
\end{tabular}

Smoking status in wave 2. ( $t$-statistics in parentheses)

the level of the longevity expectations reported in wave 2 . Both shocks lead to changes for former smokers and those who did not smoke regardless of the treatment of focal observations. These differences for current smokers display significant responses to only the smoking-related health shocks.

We use a risk-updating framework to investigate whether these differences are due to the characteristics of each group of respondents and to control for a wider array of potential contributing factors. Thus, the perceived longevity in wave 2, $P_{t}$, is hypothesized to be a weighted function of a respondent's initial longevity assessment, $P_{t-1}$, along with the unobserved risk equivalent, $r_{t}$, implied by any new information that an individual receives that would motivate a revision. Respondents are assumed to assign a precision, $\theta$, to the prior (or baseline) assessment, $P_{t-1}$ (that is, the subjective belief about longevity stated in wave 1). We also assume that people form a gauge of the precision, $\gamma$, of the beliefs implied by the new information, $r_{t}$. The posterior assessment of their odds of living to 75 or more, $P_{t}$ (their beliefs stated in wave 2), is then a weighted average of prior beliefs, scaled by the relative "information" associated with that prior $(\theta /(\theta+\gamma))$ and the new information, expressed as a risk equivalent, $r_{t}$, weighted by the relative precision $(\gamma /(\theta+\gamma))$ as in equation (1):

$$
P_{t}=\frac{\theta P_{t-1}+\gamma r_{t}}{\theta+\gamma}
$$

Our application maintains that respondents evaluate their likelihood of living to 75 or more using direct and indirect indications of their current health status as personalized information (Svenson, 1984). This longevity expectation encompasses all the information available to each individual at the time they answer the question. We include three types of measures of this information. The first involves changes in preexisting health conditions: high blood pressure, heart disease, and a smoking related cancer, all identified in wave 1. In each case, we identify the respondents for whom there has been no further deterioration in the specified health problem. Our measure of a lack of deterioration is intended to be interpreted by respondents as "positive" information, especially for cancer where the disease did not spread to new organs.

The second type of health information is the specific health shocks experienced between waves 1 and 2. As 
implied by our earlier discussion, we are assuming that the classification into (a) conditions where there is significant medical evidence linking them to smoking (that is, cardiovascular and cerebrovascular diseases, cancers related to smoking, and severe chronic lung disease (U.S. Department of Health and Human Services, 1989), and (b) other serious general health conditions are distinctive and salient to current smokers. Further confirmation that these health shocks are serious can be found in the simple analysis of confirmed deaths between waves. After controlling for age and a number of demographic variables, both of these health shock measures are positive and statistically significant influences on the likelihood that a respondent died between waves 2 and 3 with estimated marginal effects of 0.029 for smoking-related shocks and 0.025 for the general health shocks. ${ }^{17}$

The last set of variables hypothesized to signal health status to respondents involves their self-reported ability to undertake specific activities. These are classified into upperbody limitations, lower-body limitations, and fine motor limitations. Lower-body activities involve walking, climbing stairs, and changing positions. Upper-body activities involve lifting light objects, moving objects (such as a chair in a room), and getting in and out of the bathtub. Fine motor skills relate to eating, dressing, using a calculator, and picking up small objects. As with the first two sets of variables, our interest is in changes in restrictions of these activities over time.

As with the $c h i$-square analysis, our primary hypothesis is that the smoking-related $\left(S S_{t-1}\right)$ and general health $\left(G S_{t-1}\right)$ events provide new information inducing a revision of a respondent's subjective longevity beliefs. The other factors (that is, changes in preexisting conditions, $\triangle P C_{t}$, and in activity restrictions $\Delta A R_{t}$ ) could also be important to respondents' updating activities, but may require a longer timespan with sustained changes before an individual considers them relevant to his or her longevity.

Our unobservable indicator of the risk equivalent of new information, $r_{t}$, is hypothesized to be a function of these measures as in equation (2): ${ }^{18}$

$$
r_{t}=f\left(S S_{t-1}, G S_{t-1}, \Delta P C_{t}, \Delta A R_{t}\right) .
$$

Variables such as age, gender, race, and education are included to take account of how each individual's circumstances might cause them to use the new information differently. Substituting equation (2) into (1), and including $z_{1}$,

\footnotetext{
${ }^{17}$ Our analysis of the longevity updating models had to be confined to waves 1 and 2 because the prerelease version of the wave 3 records does not include the information necessary to code health shocks as smoking related and general between waves 2 and 3 .

${ }^{18}$ Several authors have used this simple updating framework to describe how subjective beliefs are revised. Some examples of these types of studies include Smith and Michaels (1987) for Chernobyl, Schulze et al. (1986) for landfills, Poe and Bishop (1992) for nitrates in drinking water, and Liu and Smith (1990) for a public risk communication program on nuclear power in Taiwan.
}

$z_{2}, \ldots, z_{k}$ to reflect demographic factors, we have a simple form of the model that Viscusi (1990) used to describe smoker's risk perceptions in equation (3):

$$
\begin{aligned}
P_{t} & =\left(\frac{\theta}{\theta+\gamma}\right) \cdot P_{t-1}+\left(\frac{\gamma}{\theta+\gamma}\right) \\
& \times f\left(S S_{t-1}, G S_{t-1}, \Delta P C_{t}, \Delta A R_{t}, z_{1}, z_{2} \ldots z_{k}\right) .
\end{aligned}
$$

There are important differences between this model and Viscusi's analysis. In his case, the measure of prior subjective beliefs, $P_{t-1}$, was not observed because he had a single cross section. Equally important, because his analysis relied on a single cross section, the only source for the updating effect hypothesized to underlie equation (3) was the difference in the information available to different demographic groups. That is, one might hypothesize that young adults with higher levels of education have greater information about smoking than do those adults who did not complete high school. Comparing the two groups, the differences in their education would be hypothesized to reflect different amounts of information. Unfortunately, there is no basis for discriminating between this explanation and one that suggests that other variables correlated with education are different.

The Viscusi estimating equation is similar to equation (4a). The effects of both $P_{t-1}$ and $r_{t}$ are assumed to be captured by the parameters for the other determinants of $P_{t}$ (that is, the $z_{j}$ 's). For notational convenience in describing our estimating equation, we combine the health shocks, $S S_{t-1}$ and $G S_{t-1}$, with our measures of changes in existing conditions, $\triangle P C_{t}$, and the changes in activity restrictions, $\Delta A R_{t}$, as well as the demographic variables. All factors are designated as $x_{j}$ 's in equation (4b). They are labeled differently from Viscusi's model because the variables that are important to our hypothesis tests cannot be measured without the panel structure. These data also offer specific information on the evolution of subjective beliefs over time (that is, both $P_{t}$ and $\left.P_{t-1}\right)$. This allows us to estimate equation (4b) and permits the role of $(\theta /(\theta+\gamma))$ to be distinguished from the influence of new health-related information. Thus, the additional sample information from the panel and the estimated parameters for the demographic variables can be used to compute separate estimates of $r_{t}$ and the precision weights that are implied by the estimated updating equations.

$$
\begin{aligned}
& P_{t}=\beta_{0}+\sum_{j=1}^{k} \beta_{j} z_{j} \\
& P_{t}=(\theta / \theta+\gamma) P_{t-1}+\alpha_{0}+\sum_{j=1}^{k} \alpha_{j} x_{j}
\end{aligned}
$$

Table 3 summarizes our primary estimates for the riskupdating models for each of the three groups: current 
smokers, former smokers, and those who never smoked. We use the responses to the "live to 75 or more" question with the two samples: "all respondents" in the first three columns and a sample composed of persons with living spouses or partners in wave 2 in the last three columns (these are labeled as the "paired sample"). All the estimates use the Heckman two-step selection framework to adjust for respondents who do not answer the longevity question as well as for observations that were deleted based on our definition of the focal responses. ${ }^{19}$ Both causes for the selection effects are treated as giving rise to one selection model.

The results to this point do not discuss the selection models used to adjust for the effects of focal observations and respondents unable to answer the longevity questions. The selection equations are specified to be a function of gender, race, age, education, proxy measures for a respondent's time horizon, indications of changes in fine motor skills, and two tests for cognitive ability. To save space, we do not report all the results here. Overall, the estimates for these selection model parameters indicate that there is fairly strong support for interpreting our definition of focal responses as being consistent with respondents who have cognitive sources for their inconsistent or non-responses to the longevity expectations questions. That is, those respondents with low scores on their cognitive tests are more likely to provide focal responses. ${ }^{20}$ Older respondents and those

\footnotetext{
${ }^{19}$ These estimated standard errors use the Heckman consistent measures. All computations were performed using STATA release 6 which reports both $\rho$ and $\lambda$ computed with the two-step parameter estimates. In response to a referee's request, we recomputed the full information estimates for the three subsamples with the full sample as defined for table 3. There were small differences in the overall conclusions about the statistical significance of each hypothesized determinant of longevity perceptions in each of the three models. Current smokers responded only to smoking-related health shocks. In addition, we also reestimated the two-step estimates for this sample deleting the other sources of selection (that is, missing values for the longevity expectations). None of our conclusions were affected by confining the selection effect to the focal observations. The selection models for focal indicated that measures of cognitive performance were positively related to being included in the sample. Thus, a non-response to the question about longevity expectations may well indicate a comparable source for the difficulty in responding. This logic was the rationale for our decision to combine the two selection effects. See Vella (1998) for discussion of the identification issues with selection models.

${ }^{20} \mathrm{~A}$ word-recall measure of cognitive ability is taken from the cognition section of the questionnaire (wave 1). The question read as follows: "Next I'll read a set of 20 words and ask you to recall as many as you can. We have purposely made the list long so that it will be difficult for anyone to recall all the words-most people recall just a few. Please listen carefully as I read the set of words. When I finish, I will ask you to recall aloud as many of the words as you can, in any order. Do you have any questions?" The words used were lake, car, army, forest, ticket, city, cabin, door, mountain, pipe, plant, bird, corn, iron, coffee, steam, cat, winter, ship, and dust. Respondents received a score ranging from 0 to 20 , corresponding to the number of words they recalled. The cognition score was obtained by asking respondents about seven relationships. They received two points for a correct answer, one point for partial credit, and none for a wrong answer. The questions read as follows: "Now I'd like you to tell me how some things are alike. In what way are an orange and a banana alike?... A table and a chair... an eye and an ear... an egg and a seed ... air and water... a fly and a tree... praise and punishment." Respondents could receive a score from 0 to 14 .
}

with less than a high school education are more likely to give focal responses.

Models are estimated for three separate samples: current smokers (S), former smokers (FS), and respondents who never smoked (NS). We repeat the same three groupings for the paired sample using the smoking status of each respondent. The paired sample has two observations for each household. The health shock variables are symmetrical. That is, if the primary respondent experienced a health shock, this is recorded as a spouse's health shock for the observation associated with the individual listed as his/her partner or spouse. Likewise, if his record suggests that a spouse experienced a shock, then that person's record includes a serious primary health shock.

A likelihood ratio test also suggests that the selection models are significantly different for the three groups. Given the important role of the cognitive ability measures in determining the ability of HRS respondents to provide nonfocal answers, this result lends some support to an early observation by Farrell and Fuchs (1986). That is, in a retrospective analysis of older individuals' health, they examined the effect of the education levels ultimately realized by these individuals on their earlier (at ages 17 through 24) smoking decisions. Using people in different birth cohorts to evaluate the role of the changing set of information about the health risks of smoking that each group would have experienced, they conclude that there appears to be one or more unobserved factors affecting both the smoking decisions and the years of schooling completed. They offer some evidence that it could be associated with cognitive ability. Our selection models indicate clear differences between the role of the cognitive ability scores in determining the ability to provide longevity responses for former smokers and nonsmokers in comparison to current smokers. This relationship between cognitive ability and focal response is less pronounced for smokers than for the other two groups, and therefore offers some support for the mechanism that may underlie Farrell and Fuchs' conjecture.

A number of variations in the specifications used for the updating models and the estimators were considered, but our conclusions do not change. The alternatives include models estimated with ordinary least squares including the focal observations, ordered probit excluding focal observations, and variations on the two stage Heckman estimator. (See note 19.) The tests for the two health shocks variables are generally consistent with the results reported in table 3 . For the ordered probit estimates, the signs of the health variables are consistent with the Heckman models and OLS results. They are significantly different from zero for the same subsamples and health shocks, but they have somewhat larger $p$-values $(p=0.08$ for the general health shock using those who never smoked was the largest of the $p$-values across models and health shocks). Tests of the differences in updating models across samples are maintained for the OLS and ordered probit estimates. Smoking 
health shocks are the only "new information" that influences current smokers' longevity expectations. The longevity expectations of the other two groups are influenced by both smoking and general health shocks. Likelihood ratio and $F$-tests generally support the conclusion that the updating models are different for the three groups. We also tested the hypothesis that, within each subsample, the individual effects of smoking- and nonsmoking-related health shocks had the same effect on longevity perceptions. It is rejected for current smokers with a $p$-value of 0.001 and could not be rejected for the other two groups: former smokers and those who never smoked. That is, in the case of the latter two groups, both types of respondents' longevity perceptions declined in response to both types of health shocks, and the magnitude of their marginal effects appears to be the same for smoking-related and general health impacts.

Several factors may explain these differences between smokers and the other groups to the general health shocks. The first is that general health shocks represent a more diverse category of effects. ${ }^{21}$ Smokers experience smokingrelated health shocks at about twice the rate of those who never smoked. Although the difference is not as pronounced with general health shocks, (6.5\% for smokers versus $4.7 \%$ for those who never smoked), the three group's rates of incidence for general health shock were also significantly different. ${ }^{22}$ Even if one believed that the general health shock variable included more measurement error, there is no reason to believe that this would have differential effects for smokers than for the other two groups.

The only explanation that appears plausible is the one suggested by the anecdotes from focus groups conducted as part of this research. ${ }^{23}$ That is, current smokers appeared more likely to use the experience of parents or grandparents to discount the relevance of health warnings for their personal decisions to smoke. That is, if their grandparents smoked and lived to a "ripe old age," the respondents acted as if the message must be irrelevant to them, given their heredity. By contrast, focus groups with former smokers conducted at the same time and using the same age groups revealed that these former smokers had experienced some

\footnotetext{
${ }^{21}$ As noted earlier, our companion analysis of the deaths between the waves suggested that both the smoking-related and the general health shocks between waves 1 and 2 were significant positive determinants of the likelihood a respondent died between waves 2 and 3 (Taylor et al., 1999). Their estimated effects were not significantly different.

22 A simple cross-tabulation and chi-square test suggest that these are significant differences in the incidence of these effects across the three subsamples: $6.5 \%$ of current smokers, $3.6 \%$ of former smokers, and $2 \%$ of those who never smoked experienced a smoking-related health shock between waves 1 and 2. General health shocks are experienced by $6.5 \%$ of smokers and in higher proportions than the smoking-related shocks for the other groups; $5.9 \%$ of former smokers and $4.7 \%$ of those who never smoked experience them. These rates are also significantly different.

${ }^{23}$ A total of three focus groups were conducted in Raleigh, NC: two on October 19 and 20 and one a month later on November 17, 1998. The objective was to evaluate how each group evaluated the risks and consequences of smoking. The sessions also evaluated different approaches to presenting information about the risks from smoking to increase the likelihood that smokers would quit or reduce the amount they smoked.
}

direct health conditions themselves or in their families. These effects are reported to have influenced their decision to quit smoking. ${ }^{24}$ In addition, it appears that current smokers require an impact specific to them personally.

The results with the other health variables reflecting both "positive" and negative changes are consistent with this interpretation. Deterioration in the upper- and lower-body activity variables are consistent negative determinants of all respondent's anticipated likelihood of living to 75 or more. These changes cause all respondents to reduce their assessment that they will live to 75 or more. The variables defined to reflect no worsening in preexisting heart disease apparently are not considered "good news." Current smokers react consistently with the other groups to the variable indicating no change in heart disease and smoking-related cancers, but not the variable for absence of a change in a preexisting blood pressure.

Our variable indicating smoking-related cancers had not spread caused respondents to increase their longevity expectations, but this effect is never a statistically significant influence to their updating (at conventional $p$-values). The longevity experience of parents is also not uniformly important to the subjective assessments of current smokers and those who never smoked. Only former smokers' longevity responses are significantly increased when either fathers were alive (for male respondents) and mothers (for females). ${ }^{25}$ Age is also only significant for one group: those who never smoked. In fact, this group is especially cognizant of nearly all the new health information-the health shocks, preexisting conditions (except cancer), worsening in activity restrictions, and, for the case of the paired sample, smoking-related health shocks experienced by a spouse. The general findings with the "all" sample are supported with the paired sample. In addition, those who never smoked responded with downward adjustment to longevity with shocks to their spouses. They also seem to be aware that a partner's smoking could reduce their personal longevity, presumably through the effects of environmental or secondhand tobacco smoke.

The differences in the three "types" of respondents' use of information may lie in each group's behavior. That is, the

\footnotetext{
${ }^{24}$ Clearly, a person's smoking status can change over time, and this could also be a result of these health shocks. We have investigated this issue in separate research and confirm that, as expected, there are links between these shocks and cessation decisions. See Taylor et al. (2000). The permanence of these changes in smoking status is difficult to evaluate with the HRS data. There is some evidence that the effects of health shocks may be differentially important over time. A simple chi-square test evaluating the effects of smoking-related health shocks experienced between waves 1 and 2 on smoking status reported in wave 3 suggests a significant difference between those experiencing the smoking-related health shocks and those who do not (comparing the mechanism implied by our findings), and no significant difference (at the 5\% level) for those who experienced general health shocks. Nonetheless, this finding should be qualified because the conclusion is a "close call." The $p$-value for the chi-square test is 0.069 .

${ }^{25}$ In focus groups conducted with current and former smokers, participants seemed to place extra credence on the longevity of their samegender parent in affecting their stated longevity expectations.
} 
process of forming a risk perception may differ according to the importance that each individual attaches to the events at risk. In the context of a more general behavioral model, we could consider the updating framework as an approximation for small changes in information. Current smokers are likely to be "risk takers" in comparison with the other two groups. As a result, they may have different propensities to acquire information (and an associated reluctance to associate it with the risky activities that they have voluntarily undertaken). This could imply that current smokers both ignore some information and weight the new information they do use in forming longevity perceptions differently.

To address this explanation, we considered two tests: equality of the risk equivalent of a smoking-related health shock across groups and a comparison of the average risk equivalent for all new health information for each group. The first of these tests normalized the coefficient of the smoking-related health shock by one minus the weight assigned to the prior longevity perception (that is, coefficient estimated for the wave 1 subjective chances of living to 75). This test computed this ratio for each group using the models reported in table 3 and used a Taylor series approximation to compute its variance. Current smokers assigned significantly greater weight to smoking-related health shocks than did former smokers with $Z=3.44$ for the paired sample; it was $Z=1.47$ for the all sample. A comparison between current smokers and those who never smoked is a closer call, with the test indicating a significant difference at about a $p$-value of $0.10(Z=1.68$ for the paired sample) and no difference with the all sample. Taking account of all household information (which was possible only with the paired sample) clearly isolated this difference in weighting, especially comparing smokers to those who never smoked.

Our second test recognizes that all the determinants of $P_{t}$ (except $P_{t-1}$ ) must be considered in estimating the risk equivalent associated with new information, $r_{t}$. To implement the second test, the reduced-form expression for the risk equivalent of the new information that is assumed to be conveyed by the health shocks is calculated for each individual using each of the statistical updating models. Estimates of $r_{t}$ are nonlinear functions of the estimated parameters and each respondent's characteristics, as in equation (5):

$$
r_{t}=\frac{\left(\hat{\alpha}_{0}+\sum_{j} \hat{\alpha}_{j} x_{j t}\right)}{1-(\hat{\theta} /(\hat{\theta}+\hat{\gamma}))} .
$$

$(\hat{\theta} /(\hat{\theta}+\hat{\gamma}))$ is the estimated parameter for $P_{t-1}$, and the remaining parameters and independent variables correspond to the other determinants (along with the intercept) in each specification of the updating model.

Table 4 reports the estimates of $r_{t}$ by sample using the models from the paired sample. In each case, we apply each subsample's estimated updating model to the observed experience of all three subsamples to estimate $r_{t}$ for each
Table 4.-Average Risk Equivalent of Wave 1 to 2 Health Changes FOR PAIRED SAMPLE UPDATING MODEL

\begin{tabular}{cccc}
\hline \hline Sample & Current Smoker & Former Smoker & Never Smoked \\
\hline Current smoker & 0.563 & 0.674 & 0.633 \\
Former smoker & $(0.033)$ & $(0.024)$ & $(0.032)$ \\
& 0.571 & 0.675 & 0.666 \\
Never smoked & $(0.036)$ & $(0.024)$ & $(0.030)$ \\
& 0.585 & 0.688 & 0.667 \\
& $(0.034)$ & $(0.022)$ & $(0.028)$ \\
\hline Estimated risk equivalents use the paired sample to estimate the updating model (table 3) and applying
\end{tabular}

Estimated risk equivalents use the paired sample to estimate the updating model (table 3) and applying it to each subsample. The numbers in parentheses are bootstrapped standard errors, allowing for selection effects and missing responses in the original paired sample. Five hundred replications were used to construct these estimated standard errors.

group as it would be implied by their own and others' use of information. This analysis is confined to the models developed from the paired sample. To permit testing, the bootstrap estimates of the standard errors are computed with 500 replications. These estimates are constructed by sampling with replacement from the paired sample of respondents to wave 2 (including missing responses and focal observations). This strategy implies that the actual sample size used in each bootstrap replication varied as it would if we could replicate the original analysis.

These results permit the effects of each group's weights for information to be separated from their actual healthrelated experiences (that is, what we have interpreted as the new information). For example, the first column applies the current smokers' updating model to the respondents from each sample's experience between the two waves. It suggests that, if smokers experienced the health records of those who never smoked, they would still interpret the new sample information about their odds of living to 75 or more to imply a lower likelihood based on what they learned between the two waves. This implied risk equivalent of the new information assigned by smokers is smaller than what those who never smoked would assign to their own health experiences.

Using the bootstrapped standard errors, it is possible to test whether the interpretation given by smokers to their own experience is significantly different from the way former smokers (or those who never smoked) would interpret the same average experience. A review of the $Z$ tests for the hypothesis of equivalent perceived risk for equivalent health experiences (that is, comparing across the rows) implies that current smokers evaluate all three records differently from former smokers. Former smokers consider the information conveyed by each set of experience about their chances of living to 75 or more to be significantly greater than do current smokers, regardless of the health experiences they encounter. The record is not as clear for comparisons of current smokers with those who never smoked. If we compare how each group evaluated their own experiences (the upper-left corner with the lower-right corner) when we hold health experience constant, the results are significantly different (at a $p$-value of 0.05 ). The comparisons of current smokers and those who never smoked are numerically consistent with our comparisons of current 
smokers and former smokers, but they are not statistically significant differences in other cases.

\section{Implications}

Our analysis takes advantages of the panel structure of the HRS and allows investigation of how people's subjective beliefs are updated in response to new information. The panel structure assures that health shocks were experienced before each respondent reports a longevity expectation. Moreover, it allows an evaluation of these expectations for the same individuals. Our specific focus was on how current smokers responded to health information in comparison to former smokers and nonsmokers. The three groups use significantly different updating rules to revise their assessments about longevity. This conclusion is robust to model specification as well as to a wide range of estimation strategies. These differences are potentially important to the design of information policies. Past work raises the behavioral puzzle that finds many smokers stating they would like to quit but also continuing to smoke (Hanson \& Logue, 1998).

The most significant stylized fact of our study documents that current smokers differ from persons who do not smoke in how information influences their personal longevity expectations. The link between health shocks and subjective assessments of longevity is more complex than previously anticipated. Prior to experiencing serious health shocks, all smokers (except the heavy smokers) seem to be somewhat fatalistic. Heavy smokers are more optimistic than their smoking behavior would warrant. When smokers experience smoking-related health shocks, they interpret this information as reducing their chances of living to 75 or more. In fact, our estimated models imply that current smokers update their longevity expectations more dramatically than either former smokers or those who never smoked. These current smokers are thus assigning a larger risk equivalent to these shocks. They do not react comparably to general health shocks, implying that specific information about smoking-related health events is most likely to cause them to update beliefs.

There is an important caveat to these shocks as information messages. Actual experiences of personal harm from smoking-related conditions have to be considered the "highwater mark" in terms of the effectiveness of informational treatments designed to alter personal risk perceptions. It remains to be evaluated whether messages can be designed that focus on the link between smoking and health outcomes in ways that will have comparable effects on smokers' risk perceptions.

\section{REFERENCES}

Evans, William N., and W. Kip Viscusi, "Estimation of State-Dependent Utility Functions Using Survey Data," this REVIEw 73 (February 1991), 94-104.
Farrell, Phillip, and Victor R. Fuchs, "Schooling and Health: The Cigarette Connection" (pp. 243-254), in V. R. Fuchs (ed.), The Health Economy (Cambridge, Mass: Harvard University Press, 1986).

Fischhoff, Baruch, A. Bostrom, and M. J. Quadrel, "Risk Perception and Communication," Annual Review of Public Health 14 (1993), 183-203.

Fischhoff, B., and D. MacGregor, "Judged Lethality: How Much People Seem to Know Depends Upon How They Are Asked," Risk Analysis 3:2 (1983), 229-235.

Hamermesh, Daniel S., "Expectations, Life Expectancy, and Economic Behavior," Quarterly Journal of Economics 100 (May 1985), 389-408.

Hanson, Jon D., and Kyle D. Logue, "The Costs of Cigarettes: The Economic Case for Ex Post Incentive-Based Regulation." Yale Law Journal 107 (March 1998), 1163-1361.

Heckman, James, "Sample Bias as a Specification Error," Econometrica 47 (January 1979), 153-162.

Hurd, Michael D., Daniel McFadden, and Li Gan, "Subjective Survival Curves and Life Cycle Behavior" (pp. 259-305), in Daniel A. Wise (Ed.), Inquiries in the Economics of Aging (Chicago: University of Chicago for NBER, 1998).

Hurd, Michael D., and Kathleen McGarry, "Evaluation of the Subjective Probabilities of Survival in the health and Retirement Study." Journal of Human Resources, Supplement 30 (September 1995), S268-S292.

Juster, F. T., and R. Suzman, "An Overview of the Health and Retirement Study." Journal of Human Resources Supplement 30 (September 1995), S7-S27.

Krupnick, Alan, and Maureen Cropper, "The Effect of Information on Health Risk Valuation." Journal of Risk and Uncertainty 5:1 (1992), 29-40.

Liu, Jin Tan, and V. Kerry Smith, "Risk Communication and Attitude Change: Taiwan's National Debate Over Nuclear Power." Journal of Risk and Uncertainty 3 (December 1990), 331-349.

Poe, G. L., and R. C. Bishop, "Measuring the Benefits of Groundwater Protection from Agricultural Contamination: Results from a TwoStage Contingent Valuation Study," University of Wisconsin-Madison unpublished working paper no. 341 (May 1992).

Pollak, Robert A., "Habit Formation and Dynamic Demand Functions," Journal of Political Economy 78 (July/August 1970), 745-763.

Saffer, Henry, "Economic Issues in Cigarette and Alcohol Advertising," Journal of Drug Issues 28:3 (1998), 781-793.

Schoenbaum, Michael, "Do Smokers Understand the Mortality Effects of Smoking? Evidence from the Health and Retirement Survey," American Journal of Public Health 87 (May 1997), 755-759.

Schulze, William D., Gary McClelland, Bren Hurd, and J. Smith, "Improving Accuracy and Reducing Costs of Environmental Benefit Assessments," vol. IV: A Case Study of a Hazardous Waste Site: Perspectives from Economies and Psychology. Draft Report, U.S. Environmental Protection Agency, Contract CR812054-01-1.

Sloan, Frank A., W. Kip Viscusi, Harrell W. Chesson, Christopher J. Conover, and Kathryn Whetten-Goldstein, "Alternative Approaches to Valuing Intangible Health Losses: The Evidence for Multiple Sclerosis," Journal of Health Economics 17:4 (1998), 475-497.

Smith, V. Kerry, and William H. Desvousges, Ann Fisher, and F. Reed Johnson, Communicating Radon Risk Effectively: A Mid-Course Evaluation. Report to U.S. Environmental Protection Agency, EPA-230-07-87-029 (July 1987).

Smith, V. Kerry, William H. Desvousges, F. Reed Johnson, and Ann Fisher, "Can Public Information Programs Affect Risk Perceptions?" Journal of Policy Analysis and Management 9 (Winter 1990), 41-59.

Smith, V. Kerry, William H. Desvousges, and John Payne, "Do Risk Information Programs Promote Mitigating Behavior?" Journal of Risk and Uncertainty 10 (May 1995), 203-221.

Smith, V. Kerry, and F. Reed Johnson, "How Do Risk Perceptions Respond to Information: The Case of Radon," this REVIEW 70 (February 1988), 1-8.

Smith, V. Kerry, and R. G. Michaels, "How Did Households Interpret Chernobyl? A Bayesian Analysis of Risk Perception," Economics Letters 23:4 (1987) 359-364. 
Svenson, Ola, "Cognitive Processes in Judging Cumulative Risk over Different Periods of Time," Organizational Behavior and Human Performance 33:1 (1984), 22-41.

Taylor, Jr., Donald H., V. Kerry Smith, and Frank A. Sloan, "Rational About Death?" Duke University unpublished manuscript (1999). , "Cigarette Smoking Cessation Dynamics for a National Sample of the Near-Elderly," Duke University, unpublished discussion paper (2000).

U.S. Department of Health and Human Services, Reducing the Health Consequences of Smoking: 25 Years of Progress, A Report of the Surgeon General, U.S. Department of Health and Human Services (1989).

U.S. Bureau of the Census, Statistical Abstract of the United States (Washington, DC: U.S. Census Bureau, 1998).

Vella, Francis, "Estimating Models with Sample Selection Bias: A Survey," The Journal of Human Resources 33:1 (1998), 127-169.

Veloso, Anabela Botelho, "Decision Making in an Adversarial Setting: A Theoretical and Experimental Investigation," unpublished doctoral dissertation, University of South Carolina (1998).
Viscusi, W. Kip, "A Bayesian Perspective on Biases in Risk Perceptions," Economics Letters 17:1 (1985), 59-62.

, "D Smokers Underestimate Risks?" Journal of Political Economy 98 (December 1990), 1253-1269.

, "Age Variations in Risk Perceptions and Smoking Decisions," this REVIEW 73 (November 1991), 577-588.

, Smoking: Making the Risky Decision (New York: Oxford University Press, 1992).

Viscusi, W. Kip, and William N. Evans, "Estimation of Revealed Probabilities and Utility Functions for Product Safety Decisions." this REVIEW 80 (February 1998), 28-33.

Viscusi, W. Kip, Wesley A. Magat, and Joel Huber, "An Investigation of the Rationality of Consumer Valuations of Multiple Health Risks," RAND Journal of Economics 18:4 (1987), 465-479.

Viscusi, W. Kip, and Charles O'Connor, "Adaptive Responses to Chemical Labeling: Are Workers Bayesian Decision Makers?" American Economic Review 74:5 (1984), 942-956. 